\title{
Criticality in English Language Literacy Teaching in an Iranian English Language Institute
}

\author{
Khadijeh Aghaei \\ Department of English Language Teaching, Gonbad Kavoos Branch \\ Islamic Azad University, Iran \\ E-mail: aghaei.khadijeh@gmail.com \\ Mojtaba Rajabi \\ Department of English Language Teaching \\ Gonbad Kavoos Branch, Islamic Azad University, Iran \\ E-mail: rajabi.m57@yahoo.com
}

Received: March 13, 2014 Accepted: May 18, 2014 Published: May 18, 2014

doi:10.5296/jse.v4i2.5283 URL: http://dx.doi.org/10.5296/jse.v4i2.5283

\begin{abstract}
This paper is a qualitative case study which aims at investigating how English language literacy teaching in an Iranian English language Institute can provide an opportunity to bring critical pedagogy into its practices. According to literacy scholars of critical pedagogic theories, research in this field is strong and ever-increasing globally; however, it is rather immature to the field of English language education in EFL contexts and needs a more in-depth analysis. Focusing on excerpts taken from literacy events in classroom interactions, and also interviews, this paper addresses the status quo of English language literacy teaching. Findings revealed that criticality in the classroom is a missed concept and classroom practices in the settings do not make learners critical persons. As a result, the learners are not provided with opportunities to read between the lines and express their voices to address the challenges in their future lives. This study also has some pedagogic recommendations on how the teacher can transform the addressed activity to lead the learners to come into the level of critical pedagogic practice in their classroom interactions.
\end{abstract}

Keywords: English Language Literacy Teaching, Literacy Event, Critical Pedagogy, EFL Context 


\section{Introduction}

In the history of English language literacy teaching in Iran, conventional pedagogy tends to encourage predefined skill implementation through textbooks. The textbooks are considered as the core of English language literacy programs and are almost "universal” elements of English language literacy teaching (Jalali, 2011; Riazi \& Mosallanejad, 2010). Both content and objectives of various syllabi, the criteria of evaluation and the way of teaching are all determined as priori by a few theoreticians. In such classroom settings, educators are needed to transfer the culture imagined in the textbooks to learners in a prescribed fashion (Riazi \& Mosallanejad, 2010) and are frowned upon if they question the legitimacy of culture, content and methodology embedded in these textbooks (Lopez, 2005; Kumaravadivelu, 2003).

Research in this field of critical pedagogy and New Literacy Studies in English language education which has recently garnered attention questions conventional pedagogies which encourage predefined skill implementation through textbooks. Research in this field is strong and ever-increasing globally; however, it is rather immature to the field of English language education in EFL contexts and needs a more in-depth analysis. This paper is a qualitative case study which aims at investigating how English language literacy teaching in an Iranian English language Institute classroom is, whether the teacher can provide an opportunity to bring critical pedagogy into his practices. Finding of this study have some implications on how English language teachers can transform their pedagogic classrooms based on the textbook to lead the learners to come into the level of critical pedagogic practice in their classroom interactions.

\section{Why New Literacy Studies in English Language Education?}

New Literacy Studies focuses on ontology and epistemology of knowledge and hence literacy practices. In fact, New Literacy Studies addresses the "what" and how and why being centred on literacy practices which are defined as cultural ways of knowing, thinking and valuing and even doing (Aghaei, Koo and Noorizah, 2012; Aghaei, Rajabi., Koo and Noorizah, 2010). To put it simpler, New Literacy Studies and specifically critical pedagogy, attempt to understand the various contexts shaping different literacy practices. It tries to comprehend how literacy practices are given worth, value and how users of literacy are situated within larger structures of ideology and power. However, the focus of English language literacy teaching in Iranian language institutes has been mainly on the what of language literacy teaching. Little, if any, attention has been paid to the how and why of language literacy teaching which not only deal with linguistic dimensions but also necessitates paying as much attention to its critical, socio-cultural aspects (Pennycook, 1990).

Critical pedagogy as a critical theory in English language literacy teaching can fill this educational void and bridge English language literacy teaching to intersections of cultural diversities and perceived differences in what it is to be, to learn and to think and to do. More precisely, in critical pedagogy, there are some educational theorists who consider English language literacy teaching to be in constant interaction with the social, cultural, political and economic realities. They believe that education systems are highly influenced by the social structures and systems and reflect ways in which the social systems have been established 
and run. Hence, critical pedagogy draws our attention to the fact that those who offer policies and make decisions about a society are usually the ones who determine the way education should be defined and practiced. That is because in all social systems one can observe examples of unequal distribution of power, marginalization, and discrimination in terms of race, gender, social class, color, language background, etc. The same biases and injustices are represented in different educational spheres. In fact, different parties in every educational system enjoy access to power to different degrees. For example, teachers are usually considered to be less expert than theorists who are often deemed to have the wisdom to think of theories and solutions and give them to teachers to practice that received wisdom almost passively (Sauvignon, 2006; Philipson, 1992; Giroux, 1983). Critical pedagogy theorists question conventional pedagogies if they enhance such domination. If so, they recommend redesigning the observed imbalances as the main concerns of English language Education.

McLaren (1998) as one of the most influential critical scholars in critical pedagogy views schools in two ways: as sorting mechanisms in which "the selections of groups of students are made on the basis of race, class, and gender; and as agencies for self and social empowerment” (p.186). In order to define critical pedagogy, he views schooling as an introduction to, preparation for, and legitimation of particular forms of social life. He believes that schooling prepares students for the support of those who have power. He points out that it is not in the best interests of those in power to produce students who critically examine the systems of power and their place in it. In fact, McLaren also argues that schools work in the interests of those with status and money, while at the same time; it makes some people marginalised because of their race, gender, or lack of wealth. In keeping with the necessity of critical pedagogy in education, McLaren (ibid) says:

Schools are meritocratic institutions as a conceptual tautology. Successful learners are those whom schools reward. If you happen to be successful, it must be because of your individual merit. Missing from this logic is recognition that students from white, affluent backgrounds are privileged over other groups, not on the basis of merit but because of the advantage that comes with having money and increased social status (p. 189).

Advocates of critical pedagogy believe that the main responsibility of language literacy teaching is to transform the society. Thus, they consider English language literacy teaching as transformative (Mayo, 2003; Kumashiro, 2000). In critical pedagogy, leaners must also find the opportunity to think about what to communicate, then, leading to find the common objectives in enriching their communicative language abilities and applying this capability to developing a consciousness raising awareness of the world (Norton \& Toohey, 2004; Crookes 1993). By applying critical pedagogy to English language literacy teaching, learners are not only given the opportunity to learn the foreign language in real context and to use it in authentic situations, but also they are given the chance to read between the lines and go beyond language literacy learning, to think and act as critically conscious subjects in the complicated contemporary era.

According to Freire (1972), “dialogue”, the two-way exchange of ideas between teachers and 
learners, is viewed as means by which critical thinking is employed to lead to "conscientiza", resulting in liberation. Specifically, his view of the notion of dialogue is more than about mere techniques; it is an epistemology, a way of knowing and behaving. Thus, dialogue ...is also an epistemology that knows the world to be a site capable of positive transformation. Dialogue is a means for worldwide change with the goal of bringing about empowerment. Freire (ibid), in his description of the qualities of true dialogue, emphasizes that "[it] cannot exist unless the dialoguers engage in critical thinking which perceives reality as a process, as transformation, rather than as a static entity” (92).

It can be concluded that education in general and English language literacy teaching and hence learning, specifically, are not neutral in nature. Educational and hence literacy visions of critical pedagogy theories are to achieve social justice and to provide a foundation for transforming unjust social conditions in every society. Critical pedagogy practitioners are those who have agency to encourage the nurturing of the intellect. They are interested in hearing different voices and readings in society. Critical pedagogy critiques the idea that knowledge production is impartial and objective. Rather, it views knowledge and hence literacy as partial, subjective, and discursive. Hence, it questions the conventional pedagogies which are centred on the textbooks. Framed in critical pedagogic approach, this study examines a situated understanding of English language literacy teaching at an EFL context i.e. an Iranian English language institute in academic year 2012-2013 as detailed in section research methodology.

\section{Research Methodology}

The methodology followed a qualitative case study. The setting, here, was an English language institute in a city situated in eastern north of Iran. The main participant in this study was an English language teacher who had been chosen based on his uninterrupted training experience and availability. Of course, the time and energy that the teacher invested in this study were compensated for either financially or professionally. Following getting agreement, the researcher met the principal of English language institute programmes to gain permission to use English language institute classroom contexts as research settings. The principal was informed of the purpose of the investigation and the received benefits that the teacher who participates in such a research may gain. Once he agreed, the participants were required to complete a participation consent form. Taking the criteria from Creswell (1998:115), the form addresses the following:

a. participant' right to voluntarily withdraw from the study at any time.

b. the central purpose of the study and procedures to be used in data collection

c. comments about protecting the confidentiality of the respondents

d. a statements about known risks associated with participation in the study

e. the expected benefits to accurate to the participants in the study

f. a place for them to sign and date the form” 
Finally, in order to meet the objective of this study, the researchers used technique of critical discourse analysis on transcribed language literacy practices (Bloome, Carter, Christian, Ottoand, Shuart- Faris, 2005). As such, it was a technique applied to analyse the transcribed observational data which here cover the manifestation of how English language literacy in such a classroom is constructed. In the preface of Bloome et al.' book (2005), Street, a pioneer in the field of literacy studies points out the capability of this framework in making a close link between their analysis of linguistic features of socio-cultural interaction with what Gee (1996) calls the "social turn" in language study that ranges from the social and cultural nature, power relations in classroom events, to the role of the teacher and the learners, which are important topics in discussions in critical pedagogy. Having used technique of critical discourse analysis on transcribed language literacy practices for the classroom, the findings as extracted themes were triangulated with the teacher's informal interviews and textbook review to depict how the teacher construct language practices centred on the foreign English language textbook more comprehensively and accurately. Furthermore, it needs to be noted that, due to word limitation, only one excerpt of a classroom literacy event in the Iranian English language institute classroom is focused to represent the status quo of English language in addressing the concept of criticality. Teacher in the classroom often reproduce a similar way of teaching and acting as discussed in findings.

\section{Findings}

This excerpt is taken from a literacy event situated in an audio-recorded conversation in New Interchange II, page 58 which practices using time to compare and contrast life in the past, in the present and in the future (see attachment, Image 1). According to classroom observations, the teacher provides implicit information and explanation for the related topic since he thinks that it can activate learners' background knowledge on the content of the activity. Hence, he says "This makes my students more focused and engaged in learning the textbook activities to understand the conversation better" (Informal interview with the teacher).

Table 1. An Excerpt of a Literacy Event in Teacher's Classroom

\begin{tabular}{|c|c|c|}
\hline Line & Participants & An Excerpt of a Literacy Event in Arman's Classroom \\
\hline 1 & \multirow{7}{*}{$\mathbf{T}$} & The conversation here is about people missing the old days. You hate your \\
\hline 2 & & school after you leave primary school .... few years later you return you see \\
\hline 3 & & that you really missed them. So this is what sometimes people miss. \\
\hline 4 & & Sometimes even unpleasant days. Page 58 right. Please close your book. \\
\hline 5 & & $((\mathrm{He}$ \\
\hline 6 & & turns on computer and tells his learners to listen to the complete \\
\hline 7 & & conversation)) SO WHO ARE THEY? \\
\hline 8 & $\mathbf{L}$ & Neighbours \\
\hline 9 & $\mathbf{T}$ & SO (.) you mean they are talking about the neighbourhood. What are they \\
\hline 10 & & actually talking about exactly? \\
\hline
\end{tabular}




\begin{tabular}{|c|c|c|}
\hline 11 & Ls & TALKING ABOUT CHANGING \\
\hline 12 & $\mathbf{T}$ & changing of the town ,of the neighbourhood \\
\hline 13 & Ls & yes \\
\hline 14 & $\mathbf{T}$ & what changes are they talking about exactly? \\
\hline 15 & $\mathbf{L}$ & population \\
\hline $\begin{array}{l}16 \\
17\end{array}$ & $\mathbf{T}$ & $\begin{array}{l}\text { first population, then growing of the population and number of cars of } \\
\text { course }\end{array}$ \\
\hline 18 & $\mathbf{L}$ & primary school \\
\hline $\begin{array}{l}19 \\
20\end{array}$ & $\mathbf{T}$ & Yeah. Their primary school. But what happened to primary school? \\
\hline 21 & $\mathbf{L}$ & changed to the mall \\
\hline 22 & $\mathbf{T}$ & exactly. It has changed to the mall and? \\
\hline 23 & $\mathbf{L}$ & $(2: 30)$ \\
\hline 24 & $\mathbf{L}$ & high school \\
\hline $\begin{array}{l}25 \\
26\end{array}$ & $\mathbf{T}$ & $\begin{array}{l}\text { No! That was primary school. They were talking about very special places } \\
\text { they had good memory of. }\end{array}$ \\
\hline 27 & $\mathbf{L}$ & the shopping eee... they buy candy \\
\hline $\begin{array}{l}28 \\
29 \\
30 \\
31 \\
32 \\
33 \\
34 \\
35 \\
36 \\
37\end{array}$ & $\mathbf{T}$ & $\begin{array}{l}\text { YES (.)The shopping... which they bought candy from grocery store. Do } \\
\text { you remember the cramps when used to go to shopping near to your } \\
\text { school? (1) You know it is a good memory in your life. You know when I } \\
\text { was school there was very small cramp shop beside out of school we used } \\
\text { to go shopping I don't know, ice cream, candy, chocolate, cookie and } \\
\text { things like that. Remember I go back to that place I'm really looking for... } \\
\text { to see that shop there... closed door. It is full of memories for us. So let's } \\
\text { go back to see what are exactly they talking about? }\end{array}$ \\
\hline $\begin{array}{l}38 \\
39\end{array}$ & Listen & $\begin{array}{l}\text { What was the neighbourhood like before? This neighbourhood sure has } \\
\text { changed. }\end{array}$ \\
\hline 40 & $\mathbf{L}$ & This neighbourhood has changed. \\
\hline 41 & $\mathbf{T}$ & NO listen again \\
\hline 42 & Listen & $\begin{array}{l}\text { What was the neighbourhood like before? This neighbourhood sure has } \\
\text { changed. I know a few years ago }\end{array}$ \\
\hline 44 & $\mathbf{L}$ & [this neighbourhood sure has changed \\
\hline 45 & $\mathbf{T}$ & This neighbourhood sure has changed. ] What is it meant by sure? \\
\hline 47 & $\mathbf{L}$ & [CERTAINLY \\
\hline
\end{tabular}


Specifically, as this excerpt of the literacy event shows (table 1), the teacher opens the interaction through asking the learners to close their books and listen to the conversation carefully. He pauses the audiotaped conversation occasionally and asks some questions such as "WHO ARE THEY" (line 7) or "what happened to primary school?" (line 19-20). These questions about the gist of the conversation help the learners to be engaged in the discussion associated with the listening text. Whenever the learners make some incomplete separate sentences from the listening text, the teacher attempts to direct them towards giving much more coherent sentences as used in the listening script:

- Learner: Neighbours

- Teacher: SO (.) you mean they are talking about the neighbourhood. What are they actually talking about exactly?

- Learner: TALKING ABOUT CHANGING

- Teacher: changing of the town ,of the neighbourhood

- Learners: yes

- Teacher: what changes are they talking about exactly?

- Learner: population

- Teacher: first population, then growing of the population and number of cars of course (lines 8-17)

Whenever he thinks that the learners may not know the meanings of words, he asks the learners for their meaning and gives a synonym for the considered word. For instance, in line 43:

- This neighbourhood sure has changed.] What is meant by sure? [CERTAINLY].

In this excerpt of interactions related to a literacy event, the teacher refers merely once to his own background knowledge and he, in fact, tries to intertextualise his explanation with the textbook conversation in order to enhance listening comprehension for the learners as shown in the following:

- YES (.)The shopping which they bought candy from grocery store. DO YOU REMEMBER THE CRAMPS ? (1) when used to go to shopping near to your school? (1) You know it is a good memory in your life. You know when I was school there was very small cramp shop beside out of school we used to go shopping I don't know um ice cream , candy, chocolate, cookie and things like that. Remember I go back to that place I'm really looking for to see that shop there closed door. It is full of memories for us. So let's go back to see < what are they talking about exactly ?> (line 28-37)

It is observed that the teacher's way of teaching mostly highlights the importance of transferring the exact information in each focused activity to the learners. For instance, he asks "What changes are they talking about exactly?”(Line 10). It seems that catching the gist 
of the text, its culture and literacy practices are very important for the teacher.

\section{Overall Commentary}

Alluding to the selected excerpt in this classroom literacy event, we can argue that this way of teaching is not enough when the teacher does not fully go beyond the text to encourage the learners to read between the lines of the text. In fact, the consequence of the domination of this kind of language literacy teaching is that it reduces the teacher's tasks to become more focused on what the foreign English language textbook prescribes or at best this excerpt of literacy event situated in a conversational activity keeps the learners informed on a variety of environmental changes in industrialised countries such as rapid diffusion of new technologies, the growth of population, rapidly changing economic structures including new types of shopping malls, multiplex businesses and entertainment buildings, and the increasing number of cars and car parking lots without discussing why and how they happened. Here, the main concern of the teacher in this classroom is to emphasize enhancing linguistic knowledge, i.e. the language skills and sub-skill activities. Both the teacher and the learners become servants of the textbook which brings about a transfer of the stereotyped cultures in the textbook.

The researchers do not want to ignore the influential role of reproducing the textbook language literacy practices in improving language skills, sub-skills, or even learners' language proficiency and literacy development. However, in our view, this teaching practice alone is not enough for effective language literacy learning because it does not ask the learner to go beyond a decontextualized and monolithic way of thinking and knowing. It merely transfers a specific culture in a predetermined and stereotyped manner to all learners. As a result, the learners cannot become more thoughtful of various ways of thinking and valuing. They cannot realize that the texts do not merely give one knowledge form and they do not always have to absorb just one knowledge form or one culture as given to them by the teacher who is the representative of the textbook. More specifically, in terms of critical pedagogic perspectives, we can argue that this way of teaching cannot transform teachers and hence learners to achieve a mutual understanding of the text produced in the classroom. Learners are not directed towards ends that they themselves have agreed upon.

Findings of this study accords FitzSimmons et al. (2013) who argumentatively mentions that the traditional ways of literacy practice construction ignore critical assessment of questions and dialogue inside a classroom setting. In these classrooms, there is no notion of plurality of cultural values. When the teacher reproduces the textbook language literacy practices, he does not create any real opportunity in the interactions to make learners engaged in discussions in critical manner, to speak about their views to these changes culturally. They ignore sharing knowledge and learning about the real facts of the society in which they live. This way of teaching cannot promote sensitivity or respect for other cultural beliefs nor a multicultural understanding which is important for the complex world. In fact, this way of language literacy practice construction is in conflict with the increasingly postmodern cultural plurality needed to characterise an [Iranian] learner with a more multicultural, 21st century civic-based notion (Koo, 2008a). To this end, this kind of language literacy practice construction deserves to be revisited so that it can promote the learners' autonomy and raise 
their cultural consciousness through ensuring cultural relevance as well. It can make them learn to explore, critique and diversify information in a variety of ways through engaging in deep analysis of textbook activities to understand and interpret various literacies in the world they are dealing with, eventually affecting a transformation among themselves (Giroux, 2001 cited in Garcia, Seglam and Share, 2013, FitzSimmons et al. 2013).

In order to achieve effective language literacy learning in the English classroom where materials and facilities are limited, the teacher can first classify the learners into different groups. The teacher can design some language literacy activities in which the learners are asked to give examples of various challenges brought about by globalisation that have had a strong influence and evolution on their lives negatively and positively. This can help the learners to seek out public engagement by cutting through the capitalist and globalisation hegemony that students are confronted in their daily practice. As critical pedagogy theorists like FitzSimmons et al. (2013) argue, a critical pedagogy can offer an interactive and deliberative classroom so that students can actively engage the world through critical knowledge and observation. Based on this pedagogy, the learners can be asked to share their views on how these changes have given rise to the growing gap between the rich and the poor, how they have had a negative or positive impact on the growing mobility of people, how everything has changed in their life, community, society, and how these changes bring about some problems for them. Why have these changes occurred? Who really benefits from these changes? How? Who suffers from these changes? Furthermore, at a higher level, based on a critical pedagogy, the teacher can also give the learners more time to develop the posed in-classroom outside classroom in their real life, and then share their new views in the classroom even when they are learning language skills and sub skills.

\section{References}

Aghaei, K. Koo Yew Lie and Noorizah Mohd Noor (2012). Sustainable Language and Literacy Learning: A Critical Trace in English Language Education. English Language Teaching Journal, 5, 6.

Aghaei, K., Rajabi, M., Koo Yew Lie and Noorizah Mohd Noor (2010). Culture: Wanted or Inevitable Dress in English as a Lingua Franca?. In Azade Shafaei, Frontiers of language and Teaching, Pp. 305-311. Universal- Publishers, Boca Raton, Florida: USA.

Bloome, D., Carter, S.P., Christian, B.M., Otto, S. \& Shuart-Faris, N (2005). Discourse Analysis and The Study of Classroom Language and Literacy Events: A Micro-Ethnographic Perspective. Mahwah: Lawrene Erbaum Associates.

Creswell, J.W. 1998. Qualitative Inquiry and Research Design: Choosing among Five Traditions. Thousand Oaks, CA: Sage Publications.

Crookes, G. (1993). Action Research for Second Language Teachers: Going beyond Teacher Research. Applied Linguistics, 14, 130-144. http://dx.doi.org/10.1093/applin/14.2.130

FitzSimmons, R., Uusiautti, S.\& Suoranta, J. (2013). An Action-oriented Critical Pedagogical Theory. Journal of Studies in Education, 3, 2. http://dx.doi.org/10.5296/jse.v3i2.3203 
Freire, P. (1972). Pedagogy of the Oppressed. New York: Continuum.

Garcia, A, Seglam, R. and Share, J. (2013). Transforming Teaching and Learning through Critical Media Literacy Pedagogy. Learning Landscapes, 6(2).

Gee, J.P. (1996). Social Linguistics and Literacies: Ideologies in Discourses. London, UK: Taylor and Francies.

Giroux, H.A. (1983). Theory and Resistance in Education: Pedagogy for the Opposition. London: Heinemann.

Jalali, M. (2011). Evaluation of an EFL English Course Book. Iranian EFL Journal, 7(5).

Koo Yew Lie, 2008b. The Politics of Cultural Production and Meaning-Making in ELT: Exploring a Reflexive Pedagogy of Pluriliteracy in Higher Education (HE). In Zailan Moris, Hajar Abdol Rahim and Shakila Abd.Manan.(eds.). Higher Education in the Asia Pacific: Emerging Trends in Teaching and Learning, pp-234-257.Penang: IPPTN/National Higher Education Research Institute (NAHERI) and University of Science Malaysia (USM) press.

Kumaravadivelu, B. (2003). Beyond Methods: Macrostrategies for Language Teaching. New Haven and London: Yale University Press.

Kumashiro, K.K. (2000). Toward a Theory of Anti-oppressive Education. Review of Educational Research, 70, 25-53. http://dx.doi.org/10.3102/00346543070001025

Marshal, C. \& Rossman, G.B. (1995). Designing qualitative research. Thousand Oaks: Sage Publication.

Mayo, P. (2003). A Rational for a Transformative Approach to Education. Journal of Transformative Education, 1, 38-57. http://dx.doi.org/10.1177/1541344602250400

McLaren, P. L. (1998). Life in Schools. An Introduction to Critical Pedagogy in the Foundations of Education (3rd ed.). New York: Longman.

Moreno-Lopez, I. (2005). Sharing Power with Students: The Critical Language Classroom. Radical Pedagogy, 7.

Norton, B. and Toohey, K. (eds). (2004). Critical Pedagogies and Language Learning. Cambridge: Cambridge University Press. http://dx.doi.org/10.1017/CBO9781139524834

Pennycook, A. (1990). Critical Pedagogy and Second Language Education. System, 18(3), 303-314. http://dx.doi.org/10.1016/0346-251X(90)90003-N

Phillipson , R. (1992). Linguistic Imperialism. Oxford University Press: Oxford.

Riazi, A. M., \& Mosallanejad, N. (2010). Evaluation of Learning Objectives in Iranian High-School and Pre-University English Textbooks Using Bloom's Taxonomy. TESL EJ, 13(4), 1-16. 
Sauvignon, S. J. (2006). Gender and Power in Applied Linguistics: An Epistemological Challenge. International Journal of Applied Linguistics, 16, 88-92. http://dx.doi.org/10.1111/j.1473-4192.2006.00107.x

\section{Attachment}

Image 1. Conversation Activity, Interchange II, p.58

\section{2) CONVERSATION This neighborhood has changed!}

A (1) Listen and practice.

Tasya: This neighborhood sure has changed:

Matt: 1 know. A few yesrs ago, not many people lived here. But the populatica is growing so fast these days.

Tanya: Yeah. It aeems like there's a construction site on every eorner.

Matt: Remember bow ve used to huy candy at that little grocery store? Now it's a multiplex cinema.

Tanya: Yeab, and they're tearing down our high school. They're kving to build a shopping mall. Soon, there will be just malls and parking lots.

Matt: That's because everyone has a car' Fify ycurs ago, people walked everywhere. Nowadays, they drive.

B (D) Listen to the rest of the conversation. What alee has changed in their neighborhood?

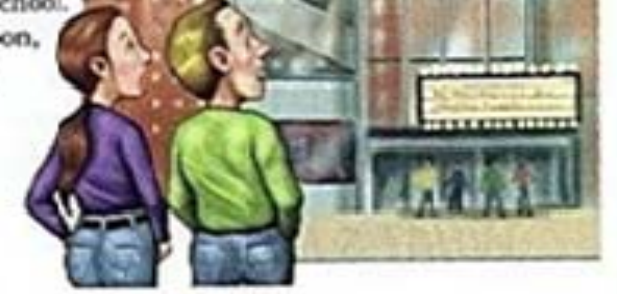

